\title{
Análise físico-química e sensorial de hambúrguer elaborado com carne de avestruz
}

\author{
Physicochemical and sensorial analyses of ostrich hamburger
}

\author{
Tiffany Prokopp HAUTRIVE ${ }^{1 *}$, Viviani Ruffo de OLIVEIRA ${ }^{1}$, Aline Roque Dutra da SILVA ${ }^{1}$, \\ Nelcindo Nascimento TERRA ${ }^{2}$, Paulo Cezar Bastianello CAMPAGNOL ${ }^{2}$
}

\section{Resumo}

O objetivo deste estudo foi elaborar um hambúrguer com carne de avestruz, para possibilitar o aproveitamento total da carne de avestruz, utilizando cortes considerados menos nobres como recortes resultantes da desossa. Avaliar sua aceitação entre potenciais consumidores, como apreciadores de carnes e hambúrgueres, bem como sugerir a industrialização e comercialização pelas indústrias como um novo produto de conveniência. Foram elaboradas três formulações de hambúrgueres com diferentes percentuais de carne de avestruz e bovina. As amostras foram analisadas por 50 provadores não treinados, escolhidos em função de gostarem e serem consumidores de hambúrgueres. O hambúrguer de formulação 2, composto por carne bovina (50\%) e carne de avestruz (50\%) obteve maior aceitação em relação aos demais. Os teores de lipídios e proteínas das amostras de hambúrgueres encontram-se dentre os valores exigidos pela legislação. Sendo assim, os hambúrgueres formulados com carne de avestruz foram bem aceitos pelos julgadores. O hambúrguer misto, o qual obteve maior aceitação, seria uma alternativa de um produto para a industrialização e comercialização, pois agregado com a carne bovina o custo dos hambúrgueres de avestruz são mais acessíveis.

Palavras-chave: carne de avestruz; hambúrguer; hambúrguer misto.

\begin{abstract}
The objective of this study was to prepare a hamburger with ostrich meat, making use of the ostrich meat cuts that are considered less noble such as those resulting form boning. This study also aimed at evaluating its acceptance among potential clients such meat and hamburger consumers as well as suggesting its industrialization as a new product. Three types of hamburgers were prepared with different percentage of ostrich and bovine meat. The samples were tested by 50 tasters without training, but who were hamburger consumers. The hamburger of formulation 2, composed by bovine meat (50\%) and ostrich meat (50\%), obtained better acceptance than the others. The contents of lipids and proteins of the hamburger samples met the values requiered by the legislation. Hence, it can be said that the ostrich meat hamburgers were well accepted by the testers. The mixed hamburger, which obtained the highest acceptance, could be an alternative product for the industrialization and commercialization because when mixed with bovine meat the cost of the ostrich hamburgers become affordable.
\end{abstract}

Keywords: ostrich meat; hamburger; mixed hamburger.

\section{Introdução}

O avestruz é uma ave, originária da África, considerada o animal mais produtivo que existe no mundo, devido à escala de produtos comercializáveis oriundos deste animal, como a carne, couro, plumas, gordura, ovos e filhotes.

No atual mercado de carnes, é dada uma atenção à carne de avestruz como uma carne rica em ácidos graxos poliinsaturados e baixo índice de gordura saturada e sódio.

Os consumidores estão se tornando cada vez mais conscientes a respeito da composição da gordura na dieta humana e o desenvolvimento de doenças cardiovasculares, pois hábitos relacionados ao estilo de vida e uma dieta rica em gorduras saturadas, colesterol e sal são fatores de risco para doenças cardiovasculares (HOFFMAN et al., 2005; LIMA et al., 2000).

Diante dessa realidade, a carne de avestruz está sendo introduzida no mercado como uma alternativa saudável, quando comparada a outras carnes vermelhas, por ser considerada bastante semelhante à carne bovina (FALVELA, 2004).
Atualmente, as tendências no processamento de carnes são na linha de produção de salsicha e hambúrguer e que permitem grande redução nos custos industriais (TERRA, 1998). O pH final elevado $(6,2)$ da carne da avestruz faz com que essa carne seja ideal para produtos processados, como hambúrgueres, salsichas, lingüiças e presuntos (HOFFMAN; MELLETT, 2003).

O hambúrguer é definido como um produto cárneo industrializado obtido da carne moída dos animais, adicionado ou não de tecido adiposo e ingredientes, moldado e submetido a processo tecnológico adequado, devendo a textura, cor, sabor e odor serem característicos (BRASIL, 2000). O hambúrguer se tornou um alimento popular pela praticidade que representa atualmente, pois possui nutrientes que alimentam e saciam a fome rapidamente, o que combina com o modo de vida que vem se instalando nos centros urbanos (ARISSETO, 2003).

Sendo assim, neste trabalho objetivou-se elaborar um hambúrguer de carne de avestruz, buscando possibilitar o

Recebido para publicação em 27/4/2007

Aceito para publicação em 15/3/2008 (002491)

${ }^{1}$ Nutrição, Centro Universitário Franciscano - UNIFRA, Santa Maria - RS, Brasil, E-mail: tiffanyhautrive@yahoo.com.br,

${ }^{2}$ Departamento de Ciência e Tecnologia de Alimentos, Centro de Ciências Rurais - CCR, Universidade Federal de Santa Maria - UFSM, Santa Maria - RS, Brasil

${ }^{*}$ A quem a correspondência deve ser enviada 
aproveitamento total da carne de avestruz, utilizando partes consideradas menos nobres como recortes resultantes da desossa. Buscou-se, portanto, avaliar sua aceitação entre potenciais consumidores, como apreciadores de carnes e hambúrgueres, realizar a análise físico-química dos hambúrgueres e sugerir a industrialização e comercialização pelas indústrias como um novo produto de conveniência.

\section{Material e métodos}

\subsection{Matéria-prima}

A amostra de carne de avestruz utilizada para este estudo foi cedida pela empresa Avestro Produtos de Avestruz S/A, localizada na cidade de Barueri, São Paulo. A carne de avestruz fornecida foi uma carne congelada sem osso do tipo Big DrumSteak (coxa externa), a uma temperatura de $-18^{\circ} \mathrm{C}$, inspecionada pelo Ministério da Agricultura sob o registro no 0002/3377. A amostra de carne bovina e os demais ingredientes utilizados durante o estudo foram adquiridos em um estabelecimento comercial do município de Santa Maria, RS.

\subsection{Elaboração do hambúrguer}

Os ingredientes utilizados na formulação dos hambúrgueres foram os sugeridos por Terra (1998): carne magra, proteína texturizada de soja, sal, pimenta branca moída, alho e cebola em pó.

A quantidade de matéria-prima utilizada nas formulações dos hambúrgueres bovino e de avestruz está expressa a seguir na Tabela 1.

Observa-se que a formulação 1 é composta por apenas carne bovina, a formulação 2 é composta por carne bovina e carne de avestruz, enquanto que a formulação 3 é composta por apenas carne de avestruz.

As carnes, após descarte de tecido conjuntivo e gordura, foram cortadas em cubos e moídas em moedor de carne manual da marca Eberle com disco de $5 \mathrm{~mm}$. Nas formulações dos hambúrgueres não foi acrescentado nenhum percentual de gordura e foram retiradas as gorduras das peças de carne antes da moagem. Após a moagem, foram adicionados os ingredientes,

Tabela 1. Matéria-prima utilizada para formulação dos hambúrgueres, Santa Maria-RS, 2006.

\begin{tabular}{lccc}
\hline \multicolumn{1}{c}{ Ingredientes } & \multicolumn{3}{c}{ Formulação (\%) } \\
\cline { 2 - 4 } & 1 & 2 & 3 \\
\hline Carne bovina & 88,72 & 44,36 & - \\
Carne de avestruz & - & 44,36 & 88,72 \\
Sal & 0,71 & 0,71 & 0,71 \\
Pimenta branca moída & 0,14 & 0,14 & 0,14 \\
Alho em pó & 0,71 & 0,71 & 0,71 \\
Cebola em pó & 0,71 & 0,71 & 0,71 \\
Proteína de soja texturizada & 3,55 & 3,55 & 3,55 \\
Gelo & 5,32 & 5,32 & 5,32 \\
Ervas finas & 0,14 & 0,14 & 0,14 \\
\hline
\end{tabular}

e a mistura homogeneizada obtida sofreu uma prensagem e moldagem com hamburgueira manual de $11 \mathrm{~cm}$ de diâmetro, obtendo-se hambúrgueres com peso líquido de $80 \mathrm{~g}$ cada. Os hambúrgueres foram envoltos por sacos de polietileno, acondicionados em cartuchos de papelão e armazenados em freezer sob a temperatura de $-18^{\circ} \mathrm{C}$, até o dia em que foi realizada a análise sensorial.

No dia da análise sensorial, os hambúrgueres foram fritos, no estado congelado, em chapa aquecida a $150{ }^{\circ} \mathrm{C}$ por 6 minutos.

A elaboração do hambúrguer e a análise sensorial foram realizadas no Laboratório de Técnica Dietética do Curso de Nutrição, do Centro Universitário Franciscano, localizado no município de Santa Maria - RS. Na Figura 1 está apresentado o fluxograma da elaboração dos hambúrgueres.

\subsection{Análise sensorial}

Para a análise sensorial dos hambúrgueres elaborados com diferentes percentuais de carne de avestruz, foi aplicado um teste de aceitação com atributos como cor, aparência, sabor e textura, com uma escala hedônica de 9 pontos, segundo metodologia citada por Anzaldúa-Moralez (1994), cujos extremos ancoram nos termos "1 - desgostei muito" e "9 - gostei muito". Além disso, foi aplicado o teste de intenção de compra do produto através de pergunta fechada, com as respostas "sim" e "não", e foram verificadas quais amostras o julgador mais gostou e menos gostou.



Figura 1. Fluxograma da elaboração dos hambúrgueres, Santa Maria - RS, 2006. 
As amostras foram analisadas por uma equipe de 50 provadores não treinados, escolhidos em função de gostarem e serem consumidores de hambúrguer, compostos por alunos de graduação, docentes e funcionários do Centro Universitário Franciscano. Cada julgador recebeu $1 / 4$ de cada formulação de hambúrguer (aproximadamente $20 \mathrm{~g}$ ), em pratos plásticos, codificados com números de três dígitos, em ordem aleatória, acompanhados de um copo de água e biscoito tipo água e sal para ser utilizado pelo provador entre as amostras, para limpeza das papilas gustativas.

A amostra de hambúrguer bovino tinha a codificação 392, a amostra de hambúrguer misto de carne de avestruz e bovino tinha a codificação 324 e a amostra do hambúrguer de carne de avestruz tinha a codificação 305 .

Este trabalho foi submetido e aprovado pelo Comitê de Ética em pesquisa da UNIFRA e todos os participantes assinaram o termo de Consentimento Livre Esclarecido, seguindo a Resolução 196/96 do CNS/MS.

\subsection{Análise física}

\section{Rendimento na cocção}

O percentual de rendimento dos hambúrgueres foi calculado pela diferença entre o peso da amostra crua e da cozida, de acordo com Berry apud Seabra et al. (2002).

\section{Capacidade de retenção de água}

A capacidade de retenção de água é uma habilidade da carne de reter a própria água contida em sua estrutura. É um parâmetro tecnológico utilizado para a indústria de carnes, pois está relacionado com a perda de peso pós-abate, com a qualidade e rendimento da carne e dos produtos cárneos. Influencia a qualidade sensorial da carne porque a perda de água no cozimento pode prejudicar a suculência e a maciez da carne (BERTRAM; ANDRESEN; KARLSSON, 2001; OLIVO, 2004 apud AGUIAR, 2006). O percentual da capacidade de retenção de água (CRA) foi calculado de acordo com Troy, Desmond, Buckey apud Seabra et al. (2002).

\subsection{Análise química}

As análises químicas foram realizadas no Laboratório de Análise Físico-química do Departamento de Tecnologia e Ciência dos Alimentos no Centro de Ciências Rurais, na Universidade Federal de Santa Maria. As análises foram realizadas nos produtos crus e em triplicata.

\section{Preparo das amostras}

Foram selecionados aleatoriamente 3 hambúrgueres de cada formulação e cortados em pedaços menores. Cada amostra foi homogeneizada em moedor de carne elétrico com discos de $5 \mathrm{~mm}$ de diâmetro. As amostras foram colocadas em frascos hermeticamente fechados e mantidos em congelador sob temperatura de $-18^{\circ} \mathrm{C}$.

\section{Composição centesimal}

As análises químicas de teor de umidade, proteína, lipídios e $\mathrm{pH}$ foram realizadas seguindo a metodologia descrita por Terra e Brum (1988).

A umidade foi determinada de acordo com o Método da estufa I, o qual se fundamenta na perda de umidade e substâncias voláteis a $105^{\circ} \mathrm{C}$.

A proteína foi determinada pelo Método de Kjeldahl, o qual se baseia na determinação do nitrogênio total. Por ocasião da digestão, em face da ação do ácido sulfúrico, o carbono é liberado como gás carbônico e o hidrogênio como água. $\mathrm{O}$ nitrogênio é transformado em amônia $\left(\mathrm{NH}_{3}\right)$ e fixado sob a forma de sal amoniacal (sulfato de amônia). Na destilação a solução concentrada de hidróxido de sódio libera a amônia que é destilada e recebida em solução de ácido sulfúrico de título conhecido com indicador adequado e, posteriormente, titulada com solução alcalinada.

Os lipídios foram extraídos através do método do butirômetro do leite, o qual se fundamenta no ataque seletivo da matéria orgânica por meio do ácido sulfúrico, com exceção da gordura que é separada por centrifugação, auxiliada pelo álcool amílico que modifica a tensão superficial.

$\mathrm{O} \mathrm{pH}$ foi determinado conforme o método do potenciômetro II, que representa a concentração de íons hidrogênio em um material. Sua determinação pode ser feita tanto com o auxílio de papel indicador como de potenciômetro (pHmetro digital da marca Digimed).

\subsection{Análise estatística}

O delineamento experimental foi o de blocos casualizados, e os dados obtidos na análise físico-química e sensorial das três formulações dos hambúrgueres foram analisados através de análise de variância (ANOVA) e teste de Tukey para a comparação das médias entre as amostras, utilizando-se um nível de significância de 5\%. Para a análise dos dados foi utilizado o programa ESTAT versão 2.0.

\section{Resultados e discussão}

\subsection{Análise sensorial}

A análise dos resultados dos atributos aparência, cor, sabor e textura das amostras de hambúrgueres com diferentes formulações está expressa na Tabela 2.

De acordo com o atributo aparência, o hambúrguer de avestruz obteve maior média em relação aos outros hambúrgueres, e diferiu significativamente $(\mathrm{p}<0,05)$ em relação ao hambúrguer bovino. A aparência da carne é uma das primeiras características observadas pelos consumidores (FANATICO et al., 2005; QIAO et al., 2002 apud AGUIAR, 2006).

Em relação ao atributo cor, não houve diferença significativa entre os hambúrgueres bovino, misto e de avestruz, apesar de estudos comprovarem que a carne de avestruz tem coloração mais vermelha e escura do que a carne bovina (FISHER; 
HOFFMAN; MELLETT, 2000). De acordo com estudo realizado por Fernández-López et al. (2006), foi observado que os hambúrgueres elaborados com carne de avestruz apresentaram uma coloração mais intensa e escura que os demais. Conforme Hoffman e Fisher (2001), a carne de avestruz se torna mais escura e mais vermelha quanto maior for a idade do animal.

No que se refere ao atributo sabor, o hambúrguer misto obteve maior média que os demais, e diferiu significativamente $(\mathrm{p}<0,05)$ em relação ao hambúrguer bovino. O hambúrguer de avestruz obteve uma média intermediária entre o hambúrguer misto e o bovino.

Quanto ao atributo textura, o hambúrguer bovino obteve menor média de aceitação quando comparado com as outras formulações, diferindo significativamente dos demais. A maciez da carne de aves está relacionada à maturidade do tecido conjuntivo, na qual as ligações químicas de colágeno são aumentadas de acordo com a idade do animal, resultando em carne mais dura e o estado de contração das proteínas miofibrilares aumenta em função da velocidade e severidade do desenvolvimento de rigor mortis. Uma carne mais dura pode passar a impressão de ser uma carne de um animal velho, no entanto, a textura pode estar associada a fatores de estresse pré-abate (FLETCHER, 2002 apud AGUIAR, 2006).

Mitau e Barbut apud Arisseto (2003), ao analisarem salsichas concluíram que os produtos com menos gordura foram mais macios e atribuíram o fato ao maior teor de umidade que esses produtos possuem. Apesar do hambúrguer de avestruz ter baixo teor de lipídios, apresentou maior teor de umidade que os demais, o que confirma que a maciez da carne de avestruz deve estar relacionada a sua umidade elevada. Porém, na análise sensorial do atributo textura, o hambúrguer misto apresentou maior aceitação que o hambúrguer de avestruz e o hambúrguer bovino.

Fernández-López et al. (2006) também compararam formulações de hambúrguer, e demonstraram que a elaboração de hambúrguer com carne de avestruz é uma opção viável devido à boa aceitação pelos julgadores.

As notas entre 6 e 9 (gostei ligeiramente a gostei muito), obtidas no teste de aceitação por atributos, sugerem que o produto poderá ser aceito no mercado consumidor sob o ponto de vista sensorial (ANZALDÚA-MORALEZ, 1994). Os hambúrgueres de avestruz, bovino e misto obtiveram valores médios entre 6 e 9 , os quais demonstram que os produtos seriam aceitos por consumidores sob o ponto de vista sensorial. Isso se comprova

Tabela 2. Valores médios dos atributos de qualidade das amostras de hambúrgueres, Santa Maria - RS, 2006.

\begin{tabular}{lccc}
\hline Atributos & $\begin{array}{c}\text { Hambúrguer } \\
\text { bovino }\end{array}$ & $\begin{array}{c}\text { Hambúrguer } \\
\text { misto }\end{array}$ & $\begin{array}{c}\text { Hambúrguer de } \\
\text { avestruz }\end{array}$ \\
\hline Aparência & $6,22^{\mathrm{b}}$ & $6,84^{\mathrm{ab}}$ & $7,26^{\mathrm{a}}$ \\
Cor & $6,86^{\mathrm{a}}$ & $6,90^{\mathrm{a}}$ & $6,98^{\mathrm{a}}$ \\
Sabor & $6,96^{\mathrm{b}}$ & $7,62^{\mathrm{a}}$ & $7,24^{\mathrm{ab}}$ \\
Textura & $6,84^{\mathrm{b}}$ & $7,8^{\mathrm{a}}$ & $7,66^{\mathrm{a}}$ \\
\hline
\end{tabular}

${ }^{\star}$ Médias seguidas de letras iguais, na mesma linha, não diferem entre si pelo Teste de

Tukey a $5 \%$ de significância $(\mathrm{p}<0,05)$. através do teste de intenção de compra, que demonstra que grande porcentagem dos julgadores compraria o produto que mais gosta.

Os resultados obtidos, em relação à amostra que os julgadores mais gostaram, apontam que $44 \%(\mathrm{n}=22)$ gostaram mais do hambúrguer misto de carne de avestruz e bovina, 34\% $(\mathrm{n}=17)$ gostaram mais do hambúrguer de carne de avestruz e $22 \%(\mathrm{n}=11)$ gostaram mais do hambúrguer de carne bovina (Figura 2).

De acordo com a amostra, a qual os julgadores menos gostaram, 56\% $(\mathrm{n}=28)$ não gostaram do hambúrguer de carne bovina, 26\% $(\mathrm{n}=13)$ não gostaram do hambúrguer de carne de avestruz e $18 \%(n=9)$ não gostaram do hambúrguer misto de carne de avestruz e bovina (Figura 3).

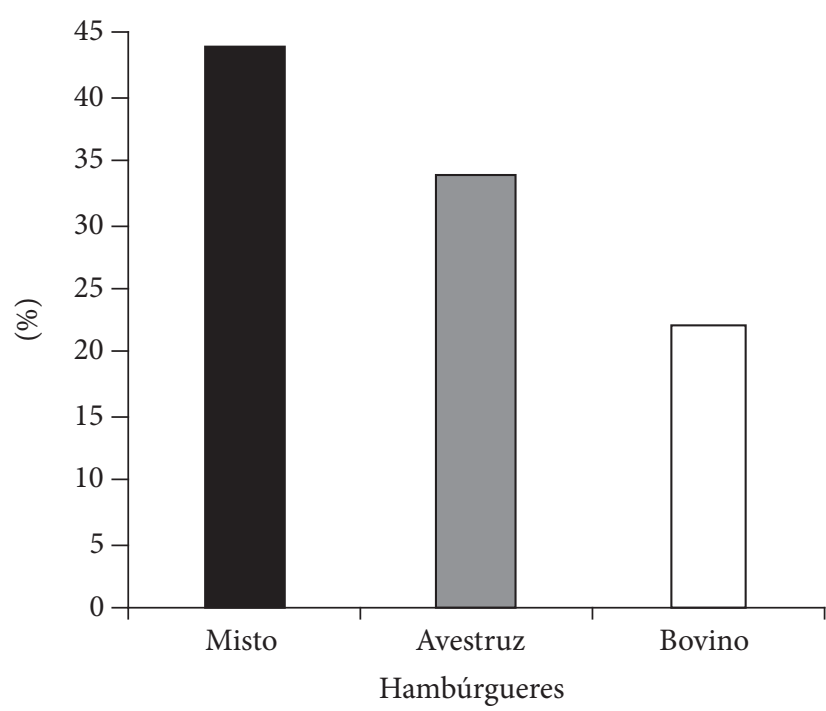

Figura 2. Porcentagem de amostras de hambúrgueres mais aceitos pelos julgadores, Santa Maria - RS, 2006.



Figura 3. Porcentagem de amostras de hambúrgueres menos aceitos pelos julgadores, Santa Maria - RS, 2006. 
O teste de intenção de compra demonstrou que 94\% $(n=47)$ dos avaliadores comprariam a amostra que mais gostaram e $6 \%(n=3)$ deles não comprariam o produto que mais gostaram (Figura 4).

Essas diferenças entre a aceitação dos hambúrgueres pelos julgadores estão relacionadas com preferências pessoais e diferentes percepções, pois nenhum provador conhecia os produtos, e devem ter comparado os hambúrgueres, durante a análise sensorial, com hambúrgueres comercializados por marcas conhecidas e vendidos em supermercados (ARISSETO, 2003).

\subsection{Rendimento na cocção e capacidade de retenção de água}

O percentual de rendimento na cocção e a capacidade de retenção de água dos hambúrgueres estão expressos na Tabela 3.

O hambúrguer de avestruz apresentou um percentual de rendimento na cocção maior se comparado com os outros hambúrgueres, com uma diferença significativa $(\mathrm{p}<0,05)$ em relação ao hambúrguer bovino, o qual teve menor rendimento na cocção.

A capacidade de retenção de água não demonstrou diferença significativa entre as formulações de hambúrgueres. Porém, um estudo realizado comparando a perda de água por gotejamento entre carne bovina, frango, porco e avestruz

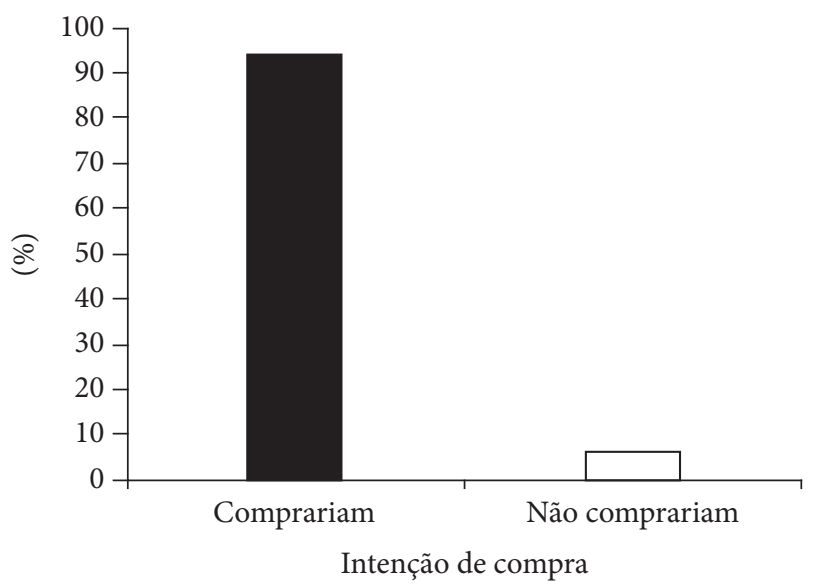

Figura 4. Teste de intenção de compra dos hambúrgueres, Santa Maria - RS, 2006.

Tabela 3. Percentual de rendimento na cocção dos hambúrgueres e capacidade de retenção de água dos hambúrgueres, Santa Maria - RS, 2006.

\begin{tabular}{lccc}
\hline \multicolumn{1}{c}{ Percentual } & $\begin{array}{c}\text { Hambúrguer } \\
\text { de avestruz }\end{array}$ & $\begin{array}{c}\text { Hambúrguer } \\
\text { misto }\end{array}$ & $\begin{array}{c}\text { Hambúrguer } \\
\text { bovino }\end{array}$ \\
\hline $\begin{array}{l}\text { Rendimento na } \\
\text { cocção (\%) }\end{array}$ & $77,5^{\mathrm{a}}$ & $74,6^{\mathrm{ab}}$ & $69,2^{\mathrm{b}}$ \\
$\begin{array}{l}\text { Capacidade de } \\
\text { retenção de água (\%) }\end{array}$ & $98,0^{\mathrm{a}}$ & $98,0^{\mathrm{a}}$ & $98,0^{\mathrm{a}}$ \\
\hline
\end{tabular}

* Médias seguidas de letras iguais, nas mesmas linhas, não diferem entre si pelo teste de Tukey a $5 \%$ de significância $(\mathrm{p}<0,05)$. divergiu do resultado deste estudo, pois a carne de avestruz foi a que menos perdeu água. A perda pelo gotejamento é um problema para o comerciante, porque reduz o peso da carne e causa um acúmulo de líquido em torno da mesma, causando uma rejeição do consumidor, devido sua aparência desagradável. As propriedades físicas da carne (cor e textura na carne crua) e a aceitação dependem de sua capacidade de não perder água (MORÓN-FUENMAYOR; ZAMORANO-GARCÍA, 2003).

\subsection{Composição centesimal}

Os dados referentes à composição centesimal dos hambúrgueres encontram-se na Tabela 4.

Como pode ser observado, os valores de $\mathrm{pH}$ das amostras estudadas diferiram significativamente $(\mathrm{p}<0,05)$ entre si. $\mathrm{O} \mathrm{pH}$ do hambúrguer de avestruz foi mais elevado quando comparado com o pH dos hambúrgueres misto e bovino. Este alto valor de $\mathrm{pH}$ do hambúrguer de avestruz se deve ao fato de que a carne de avestruz possui um $\mathrm{pH}$ mais elevado que outras carnes. Fernández-López et al. (2006) relataram que a carne de avestruz teve $\mathrm{pH}$ 6,2, valor semelhante ao encontrado neste estudo.

$\mathrm{O}$ pH de 5,8 a 6,2 indica que a carne está aceitável para o consumo, pH de 6,4 mostra que a carne é recomendada apenas para o consumo imediato e $\mathrm{pH}$ acima de 6,4 indica que a carne está em início de decomposição (TERRA; BRUM, 1988). Os hambúrgueres de carne de avestruz e o misto apresentaramse com o pH dentro desses limites da normalidade, porém o hambúrguer bovino apresentou $\mathrm{pH}$ um pouco abaixo desses valores.

Em relação ao teor de umidade, o hambúrguer de avestruz teve maior porcentagem dos demais hambúrgueres e houve diferença estatística $(\mathrm{p}<0,05)$ em relação ao hambúrguer bovino. Os resultados encontrados por Sales e Hayes (1996) corroboram com os resultados deste estudo, em que a carne de avestruz teve um teor de umidade maior que a carne bovina e de aves. Paleari et al. (1998) encontraram valores de umidade da carne de avestruz $(75,1 \%)$ e bovina $(74,2 \%)$ semelhantes a este estudo.

Os valores de proteínas das amostras estudadas não apresentaram diferenças estatísticas entre si. Porém, a carne bovina apresentou uma porcentagem maior de proteína em relação aos outros hambúrgueres. Paleari et al. (1998) compararam a carne de avestruz com a carne de peru e a bovina, e observaram que a carne de avestruz apresentou mais proteínas do que as outras carnes. Sales e Hayes (1996), em estudo comparando a compo-

Tabela 4. Composição centesimal dos hambúrgueres de avestruz, misto e bovino, Santa Maria - RS, 2006.

\begin{tabular}{lcccc}
\hline \multicolumn{1}{c}{ Amostras } & $\mathrm{pH}$ & $\begin{array}{c}\text { Umidade } \\
(\%)\end{array}$ & $\begin{array}{c}\text { Proteína } \\
(\%)\end{array}$ & $\begin{array}{c}\text { Lipídios } \\
(\%)\end{array}$ \\
\hline Hambúrguer de avestruz & $6,23^{\mathrm{a}}$ & $76,26^{\mathrm{a}}$ & $19,74^{\mathrm{a}}$ & $0,45^{\mathrm{b}}$ \\
Hambúrguer misto & $5,98^{\mathrm{b}}$ & $75,17^{\mathrm{ab}}$ & $20,70^{\mathrm{a}}$ & $0,83^{\mathrm{b}}$ \\
Hambúrguer bovino & $5,63^{\mathrm{c}}$ & $74,70^{\mathrm{b}}$ & $21,28^{\mathrm{a}}$ & $1,6^{\mathrm{a}}$ \\
\hline
\end{tabular}

${ }^{*}$ Médias seguidas de letras iguais, nas mesmas colunas, não diferem entre si pelo teste de Tukey a $5 \%$ de significância $(\mathrm{p}<0,05)$. 
sição nutricional das carnes de avestruz, boi e frango, também encontraram um índice de proteína maior na carne de avestruz. Sales e Hayes (1996), Paleari et al. (1998) encontraram resultados que divergiram do teor de proteína encontrados neste estudo.

O hambúrguer com maior teor de lipídios foi o hambúrguer bovino, o qual apresentou 3,5 vezes mais lipídios que o hambúrguer de avestruz que teve o menor índice de gordura. $\mathrm{O}$ hambúrguer bovino apresentou diferenças $(\mathrm{p}<0,05)$ em relação ao hambúrguer de avestruz. Paleari et al. (1998) comprovaram que o índice de gordura saturada e o colesterol são menores na carne de avestruz se comparada com o peru, e a porcentagem de gordura insaturada é maior na carne de avestruz. Diferente das outras carnes, a carne de avestruz possui baixo teor de lipídios, pois $100 \mathrm{~g}$ de carne contém 2 a $3 \mathrm{~g}$ de gordura, 76 a $96 \mathrm{mg}$ de colesterol e 120 a $130 \mathrm{kcal}$ (MORRIS, 1996). Morris (1996) encontrou um teor de lipídios para a carne de avestruz maior que o encontrado nesta pesquisa.

Na legislação de alimentos nos Estados Unidos, a rotulagem de um produto como baixo teor de gordura requer menos que $10 \%$ e, como extramagro menos que $5 \%$ de gordura (BARBUT; MITTAL, 1993 apud ARISSETO, 2003). Apesar do hambúrguer bovino apresentar maior teor de lipídios que os demais, as três formulações apresentaram índices de lipídios menores que $5 \%$, podendo classificá-los como hambúrgueres extramagros. Este baixo índice de gordura encontrado nos hambúrgueres se deve ao fato de que nas formulações dos hambúrgueres não foi acrescentado nenhum percentual de gordura e foram retiradas as gorduras das peças de carne antes da moagem.

A gordura melhora a palatabilidade pelo aumento da maciez e suculência, mas em alguns produtos não existe relação entre esses parâmetros (JIMEENEZ-COLMENERO, 2000 apud ARISSETO, 2003).

Os hambúrgueres devem atender as seguintes características físico-químicas: $23 \%$ de gordura (máxima), 15\% proteína (mínima) e 3\% de carboidratos totais (BRASIL, 2000). Os teores de lipídios e proteínas das amostras de hambúrgueres estudadas encontram-se dentre os valores exigidos pela legislação brasileira.

Os valores obtidos na composição centesimal do hambúrguer de carne de avestruz são semelhantes aos encontrados por Sales e Hayes (1996), que verificaram a composição da carne de avestruz. Porém, em relação à carne bovina, os mesmos autores encontraram um percentual de $6 \%$ de lipídios, diferente do que foi encontrado neste estudo ( $1,6 \%)$, devido à retirada de gordura da peça cárnea.

A composição nutricional da carne magra corresponde a $75 \%$ de umidade, $20 \%$ de proteína, $3 \%$ de lipídios e $2 \%$ de sustâncias solúveis não nitrogenadas (SCHMIDT, 1994). A composição nutricional dos hambúrgueres elaborados estão semelhantes composição nutricional de uma carne magra.

De acordo com a composição química da carne de avestruz, sugere-se que os produtos processados derivados da carne de avestruz podem ser formulados para competir com sucesso com os tipos similares de produtos derivados de outras espécies de carne (FISHER; HOFFMAN; MELLETT, 2000).

\section{Conclusões}

Os resultados deste estudo indicaram que os hambúrgueres elaborados tiveram uma boa aceitação pelos consumidores, que foi demonstrada pelo elevado índice de intenção de compra.

Os hambúrgueres tiveram textura, cor, sabor e aparência característicos do produto e atenderam às necessidades nutricionais de proteína e lipídios, conforme exige a legislação brasileira.

Vale ressaltar que o hambúrguer misto, que obteve maior aceitação pelos julgadores, seria uma alternativa de produto para a industrialização e comercialização, pois agregado com a carne bovina o custo dos hambúrgueres de avestruz seria menos oneroso.

O baixo teor de lipídios nos hambúrgueres o torna um alimento ideal para pacientes dislipidêmicos e consumidores que queiram ter uma alimentação com baixo teor de gordura saturada.

A fabricação dos hambúrgueres de carne da avestruz é uma opção para as indústrias que queiram aproveitar totalmente a carne de avestruz utilizando cortes considerados menos nobres, como recortes resultantes da desossa na fabricação de um novo produto buscando agregação de valor.

Faz-se necessário que estudos complementares em relação à maciez objetiva, cor (escala CIE L, a, b), perfil de ácidos graxos e quantificação do colesterol nos hambúrgueres elaborados seriam pertinentes em um próximo trabalho, pois a carne de avestruz está sendo introduzida no mercado brasileiro gradativamente como uma alternativa de carne vermelha. Há poucos estudos realizados com carne de avestruz, mas alguns comprovam que é a opção mais saudável comparada com outras carnes.

\section{Agradecimentos}

Os autores agradecem à empresa Avestro Produtos de Avestruz S/A, pelo fornecimento da carne de avestruz utilizada durante a pesquisa.

\section{Referências bibliográficas}

AGUIAR, A. P. S. Opinião do consumidor e qualidade da carne de frangos criados em diferentes sistemas de produção. Piracicaba, 2006. 71p. Dissertação - (Mestrado em Ciência e Tecnologia dos Alimentos), Escola Superior de Agricultura Luiz de Queiroz, Universidade de São Paulo.

ANZALDÚA-MORALEZ, A. La evaluación sensorial de los alimentos em la teoría y la práctica. Zaragoza: Editorial Acribia S.A, 1994. $220 \mathrm{p}$.

ARISSETO, A. P. Avaliação da qualidade global do hambúrguer tipo calabresa com reduzidos teores de nitrito. São Paulo, 2003. 145 p. Dissertação - (Mestrado em Engenharia de Alimentos), Faculdade de Engenharia de Alimentos, Universidade Estadual de Campinas (UNICAMP).

BRASIL. Ministério da Saúde. Agência Nacional de Vigilância Sanitária. Instrução Normativa no $\mathbf{2 0 / 2 0 0 0}$. Regulamento Técnico de Identidade e Qualidade do Hambúrguer. Brasília, 2000. Disponível em: <http://www.agricultura.gov.br>. Acesso em: 16/06/2006. 
Resolução no 196, de 10 de outubro de 1996. Estabelece os requisitos para realização de pesquisa clínica de produtos para saúde utilizando seres humanos Conselho Nacional de Saúde. Brasília, 10 out. 1996. Disponível em http://e-legis.anvisa.gov.br/leisref/public/ showAct.php?id=663. Acesso em: 22/05/2006.

FALVELA, C. V. Carne de avestruz. Revista Nutrição Brasil, v. 3, n. 1, p. 51-54, jan. 2004.

FERNÁNDEZ-LÓPEZ, J. et al. Quality characteristics of ostrich (Struthio camelus) burgers. Meat Science, v. 73, n. 2, p. 295-303, 2006.

FISHER, P.; HOFFMAN, L. C.; MELLETT, F. D. Processing and nutritional characteristics of value added ostrich products. Meat Science, v. 55, n. 2, p. 251-254, 2000.

HOFFMAN, L. C.; FISHER, P. Comparison of meat quality characteristics between young and old ostriches. Meat Science, v. 59, n. 3, p. 335-337, 2001.

HOFFMAN, L. C. et al. The effect of dietary fish oil rich in $n_{-} 3$ fatty acids on the organoleptic, fatty acid and physicochemical characteristics of ostrich meat. Meat Science, v. 70, n. 1, p. 45-53, 2005.

HOFFMAN, L. C.; MELLETT, F. D. Quality characteristics of low fat ostrich meat patties formulated with either pork lard or modified corn starch, soya isolate and water. Meat Science, v. 65, n. 2, p. 869-875, 2003.

LIMA, F. E. L. Ácidos graxos e doenças cardiovasculares: uma revisão. Revista de Nutrição, v. 13, n. 2, p. 73-80, maio/ago, 2000.
MORRIS, C. Ostrich meat. In: DRENOWATZ, C. The Ratite Encyclopedia. Texas: Ratite Records, 1996. p. 159-165.

MORÓN-FUENMAYOR, O. E.; ZAMORANO-GARCÍA, L. Pérdida por goteo en diferentes carnes crudas. Archivos Latinoamericanos de Prodúccion Animal, v. 11, n. 2, p. 125-127, 2003.

PALEARI, M. A. et al. Ostrich meat: physico-chemical characteristics and comparison with turkey and bovine meat. Meat Science, v. 48 , n. 3/4, p. 205-210, 1998.

SALES, J.; HAYES, J. P. Proximate, amino acid and mineral composition of ostrich meat. Food Chemistry, v. 56, n. 2, p. 167-170, 1996.

SCHIMIDT, G. R. Comportamiento funcional de los componentes de la carne durante el procesado. In: PRICE, J. F.; SCHWEIGERT, B. S. Ciencia de la carne y de los productos cárnicos. Zaragoza: Editorial Acribia, 1994. 377 p.

SEABRA, L. et al. Fécula de mandioca e farinha de aveia como substitutos de gordura na formulação de hambúrguer de carne ovina. Ciência e Tecnologia dos Alimentos, v. 22, n. 3, p. 245-248, set./dez, 2002.

TERRA, N. N. Apontamentos de tecnologia de carnes. São Leopoldo: Editora Unisinos, 1998. 216 p.

TERRA, N. N.; BRUM, M. A. R. Carne e seus derivados: técnicas de controle de qualidade. São Paulo: Nobel, 1988. 119 p.

UNESP. Faculdade de Ciências Agrárias e Veterinárias. ESTAT Sistema para Análises Estatísticas. Versão 2.0. Jaboticabal, 1999. 1 disquete. 